\title{
PENGARUH PRODUKSI AIR MATA TERHADAP DRY EYE SYNDROME PADA PASIEN DI POLIKLINIK MATA RUMAH SAKIT PERTAMINA BINTANG AMIN BANDAR LAMPUNG TAHUN 2018
}

\author{
Rahmat Syuhada ${ }^{1}$, Muhammad Wahid Syahputra ${ }^{2}$
}

${ }^{1}$ Departemen Penyakit Mata, Rumah Sakit Pertamina Bintang Amin
2Prodi Pendidikan Dokter Fakultas Kedokteran, Universitas Malahayati

\begin{abstract}
ABSTRAK
Sindrom mata kering atau dry eye syndrome adalah penyakit multifaktorial dari air mata dan permukaan okuler yang mengakibatkan gejala ketidaknyamanan, gangguan visual, dan ketidakstabilan film air mata dengan potensi kerusakan pada permukaan mata.Beberapa faktor lingkungan diyakini mempengaruhi kejadian dry eye syndrome, termasuk produksi air mata dan evaporasi yang disebabkan oleh polusi, ketinggian, angin, dan udara. Tujuan penelitian ini adalah untuk mengetahui pengaruh produksi air mata terhadap dry eye syndrome.Analitik melalui studi observasi dengan pendekatan cross sectional. Jumlah sampel 30 orang dan diambil dengan purposive sampling. Data penelitian diperoleh dari hasil uji Schirmer pada responden. Analisis data univariat dan bivariat dilakukan dengan uji chi-square.Distribusi frekuensi responden paling banyak pada kategori berikut; usia 26-35 tahun (22 orang, 73,3\%), jenis kelamin perempuan (20 orang, 66,7\%), produksi air mata normal (20 orang, 66,7\%), dan dry eye syndrome (19 orang, 63,3\%). Terdapat hubungan bermakna antara produksi air mata dengan dry eye syndrome $(p=0,032, O R=9,00)$.Terdapat hubungan bermakna antara produksi air mata dengan dry eye syndrome.
\end{abstract}

Kata kunci :Produksi Air Mata, Schirmer, Mata Kering

\section{Latar Belakang}

Sindrom mata kering atau dry eye syndrome adalah penyakit multifaktorial dari air mata dan permukaan okuler yang mengakibatkan gejala ketidaknyamanan, gangguan visual, dan ketidakstabilan film air mata dengan potensi kerusakan pada permukaan mata. Penyakit ini disertai dengan peningkatan osmolaritas air mata dan peradangan permukaan okuler (Craig et al., 2017). Dry eye bisa memberikan keluhan ringan sampai berat. Beberapa studi menunjukkan bahwa sindrom mata kering dapat memiliki dampak besar terhadap fungsi visual, aktivitas seharihari, fungsi sosial dan fisik, produktivitas kerja, biaya langsung dan tidak langsung dari penyakit, dan kualitas hidup. Komplikasi tahap lanjut dari dry eye adalah keratitis, ulkus dan selanjutnya dapat menimbulkan kebutaan (RiordanEva dan Augsburger, 2017).
Sindrom mata kering adalah kondisi umum yang secara negatif mempengaruhi fungsi fisik dan mental. Beberapa faktor lingkungan diyakini mempengaruhi kejadian dry eye syndrome, termasuk polusi ketinggian, angin, dan udara(Galor et al., 2014).Berdasarkan literatur yang ada, disebutkan bahwa kejadian sindroma mata kering di Amerika dan sekitarnya berkisar $7,8 \%$ dari total populasi, sedangkan di Asia mencapai 93,2\% dari total populasi. Hal ini dapat terjadi karena dua hal: pertama, secara lokasi geografi dan populasi yang didapatkan, kedua, tidak ada standarisasi dari tiap populasi dalam pengukuran sindrom mata kering baik itu berdasarkan kuesioner, tes, dan pengetahuan tentang kriteria diagnostik sindroma mata kering (Basak et al., 2012).

Sistem sekresi air mata atau lakrimal terletak di daerah temporal bola 
mata. Sistem eksresi mulai pada pungtum lakrimal, kanalikuli lakrimal, sakus lakrimal, duktus nasolakrimal, meatus inferior. Sistem lakrimal terdiri atas 2 bagian, yaitu: Sistem produksi atau glandula lakrimal yang terletak di temporo antero superior rongga orbita, dan sistem eksresi yang terdiri dari pungtum lakrimal, kanalikuli lakrimal, sakus lakrimal, dan duktus nasolakrimal. Film air mata sangat berguna untuk kesehatan mata (Ilyas dan Yulianti, 2014).

Mekanisme inti mata kering diyakini karena hiperosmolaritas air mata dan ketidakstabilan film air mata. Hiperosmolaritas air mata menyebabkan kerusakan pada epitel permukaan dengan mengaktifkan kaskade kejadian inflamasi pada permukaan mata dan pelepasan mediator inflamasi ke dalam air mata. Kerusakan epitel melibatkan kematian sel oleh apoptosis, hilangnya sel goblet, dan gangguan musin yang mngakibatkan ketidakstabilan lapisan air mata. Ketidakstabilan ini memperparah hiperosmolaritas permukaan mata dan dapat juga diprakarsai oleh beberapa etiologi, termasuk obat-obatan xerosis, xeroftalmia, alergi mata, penggunaan pengawet topikal, dan memakai lensa kontak. Cedera epitel yang disebabkan oleh mata kering merangsang ujung saraf kornea, menyebabkan gejala ketidaknyamanan dan peningkatan berkedip (American Academy of Ophtalmology, 2018).

Sindrom mata kering dapat didiagnosis melalui pemeriksaan mata yang komprehensif. Pengujian, dengan penekanan khusus pada evaluasi kelopak mata dan permukaan depan bola mata, termasuk pengukuran dan evaluasi produksi air mata.

\section{Metodologi}

Analitik melalui studi observasi dengan pendekatan cross sectional. Jumlah sampel 30 orang dan diambil dengan purposive sampling. Data penelitian diperoleh dari hasil uji Schirmer pada responden. Analisis data univariat dan bivariat dilakukan dengan uji chi-square. Dengan kriteria inklusi yaitu:Bersedia menjadi sampel penelitian dan dilakukan pemeriksaan Uji Schirmer, Dilakukan uji untuk mengetahui kuantitas produksi air mata pada kedua mata, baik yang terkena dan tidak.Kriteria Ekslusi yaitu: Pasien tidak kooperatif, Pasien yang menggunakan obat yang bisa mempengaruhi produksi air mata (terapi estrogen, penggunaan anti histamin), Sedang menderita penyakit mata lain (contoh: keratitis, konjungtivitis, glaukoma).

\section{Hasil Penelitian}

Tabel 1. Karakteristik Responden

\begin{tabular}{lcc}
\hline Kategori & Jumlah & Persentase \\
\hline Usia & 3 & \\
$<25$ Tahun & 22 & 10,0 \\
$26-35$ Tahun & 5 & 73,3 \\
$36-45$ Tahun & & 16,7 \\
\hline Jenis Kelamin & 20 & 66,7 \\
Perempuan & 10 & 33,3 \\
Laki-laki & $\mathbf{3 0}$ & $\mathbf{1 0 0}$ \\
\hline Total & &
\end{tabular}

Berdasarkan tabel 1. dapat diketahui analisis univariat pada masingmasing variabel.Frekuensi terbanyak adalah sebagai berikut; usia $26-35$ tahun (22 orang, 73,3\%), dan jenis kelamin perempuan (20 orang, 66,7\%). 
Tabel 2. Distribusi Frekuensi Produksi Air Mata Pada Responden

\begin{tabular}{lcc}
\hline Produksi Air Mata & Jumlah & Persentase \\
\hline Normal & 20 & 66,7 \\
Terganggu & 10 & 33,7 \\
\hline Total & $\mathbf{3 0}$ & $\mathbf{1 0 0}$ \\
\hline
\end{tabular}

Berdasarkan tabel 2. dapat dapat diketahui bahwa distribusi frekuensi responden berdasarkan produksi air mata secara berturut-turut pada kategori bukan normal sebanyak 20 orang $(66,7 \%)$, dan pada kategori terganggu sebanyak 10 orang $(33,7 \%)$.

Tabel 3. Distribusi Frekuensi Dry Eye Syndrome Pada Responden

\begin{tabular}{lcc}
\hline Dry Eye Syndrome & Jumlah & Persentase \\
\hline Bukan Dry Eye Syndrome & 11 & 36,7 \\
Dry Eye Syndrome & 19 & 63,3 \\
\hline Total & $\mathbf{3 0}$ & $\mathbf{1 0 0}$ \\
\hline & & pada kategori bukan dry eye syndrome \\
dapat diketahui bahwa distribusi & $\begin{array}{l}\text { sebanyak 11 orang (36,7\%), dan pada } \\
\text { kategori dry eye syndrome sebanyak 19 }\end{array}$ \\
frekuensi responden berdasarkan dry & orang (63,3\%).
\end{tabular}

eye syndrome secara berturut-turut

Tabel 4. Distribusi Responden Menurut Produksi Air Mata dan Dry Eye Syndrome Pada Responden

\begin{tabular}{|c|c|c|c|c|c|c|c|c|}
\hline \multirow{3}{*}{$\begin{array}{l}\text { Produksi Air } \\
\text { Mata }\end{array}$} & \multicolumn{4}{|c|}{ Dry Eye Syndrome } & & & \multirow{3}{*}{ p value } & \multirow{3}{*}{ OR } \\
\hline & \multicolumn{2}{|c|}{$\begin{array}{c}\text { Bukan dry eye } \\
\text { syndrome }\end{array}$} & \multicolumn{2}{|c|}{$\begin{array}{l}\text { Dry eye } \\
\text { syndrome }\end{array}$} & \multicolumn{2}{|c|}{ Total } & & \\
\hline & $\mathrm{n}$ & $\%$ & $\mathrm{n}$ & $\%$ & $n$ & $\%$ & & \\
\hline Normal & 10 & 90,9 & 1 & 9,1 & 11 & 100 & 0,032 & \\
\hline Terganggu & 10 & 52,6 & 9 & 47,6 & 19 & 100 & & $\begin{array}{c}9,00 \\
(0,95- \\
84,89)\end{array}$ \\
\hline Total & 20 & 66,7 & 10 & 33,7 & 30 & 100 & & \\
\hline
\end{tabular}

Hasil analisis hubungan antara produksi air mata dengan dry eye syndrome diperoleh bahwa di antara 11 responden yang mengalami produksi air mata normal, ada sebanyak 10 orang $(90,9 \%)$ yang bukan pasien dry eye syndrome dan 1 orang $(9,1 \%)$ yang menderita dry eye syndrome. Sementara di antara 19 responden yang mengalami penurunan produksi air mata, ada sebanyak 10 orang $(52,6 \%)$ yang bukan pasien dry eye syndrome dan 9 orang $(47,6 \%)$ yang menderita dry eye syndrome. Hasil uji statistik chi-square diperoleh nilai $p=0,032(<0,05)$, maka Ho ditolak dan dapat disimpulkan bahwa terdapat hubungan antara produksi air matadengan dry eye syndrome. Dari hasil analisis diperoleh pula nilai
$\mathrm{OR}=9,00$ artinya responden yang mengalami penurunan produksi air mata mempunyai resiko 9,00 kali lebih besar untuk terkena dry eye syndrome dibandingkan dengan responden yang tidak mengalami penurunan produksi air mata. Nilai confidence interval yang didapat adalah 0,95-84,89.

\section{Pembahasan}

Kejadian dry eye syndrome menurut penelitian yang dilakukan di United States oleh Women's Health Study (WHS) dan Physician's Health Study (PHS) didapatkan bahwa 4,8 juta penduduk Amerika berusia di atas 50 tahun menderita dry eye syndrome(Tear Film and Ocular Surface Society, 
2007). Hasil yang tidak jauh berbeda juga ditemukan bahwa pada penelitian yang menunjukkan bahwa prevalensi $d r y$ eye syndrome tertinggi berada pada rentang usia 60-69 tahun sebesar $51,4 \%$ (Kasetsuwan et al., 2012). Penelitian lain juga menyatakan jumlah pasien dry eye syndrome tertinggi berada pada rentang umur 31-40 tahun sebesar 20\% (Sahai dan Malik, 2005). Sedangkan pada penelitian ini didapatkan pasien dry eye syndrome dengan jumlah terbanyak berada pada rentang usia 26-35 tahun, sebanyak 22 orang $(73,3 \%)$. Hasil distribusi pasien dry eye syndrome pada rentang umur bisa saja bervariasi, hal ini disebabkan oleh faktor lain seperti demografis, jenis pekerjaan, atau paparan terhadap lingkungan seperti paparan terhadap matahari, angin, ataupun temperatur yang tinggi (Sahai dan Malik, 2005).

Pada penelitian ini didapatkan prevalensi jenis kelamin terbanyak adalah perempuan (20 orang, 66,7\%). Prevalensi dry eye syndrome berdasarkan jenis kelamin dapat terjadi pada siapa saja, baik pada laki-laki maupun perempuan.Akan tetapi pada beberapa penelitian epidemiologi menunjukkan adanya prevalensi yang lebih tinggi pada perempuan dibandingkan laki-laki(Chaironika, 2011). Hasil sebuah studi didapatkan lebih banyak pasien dry eye syndrome yang berjenis kelamin perempuan (25\%) daripada laki-laki $(17,2 \%)$. Hal ini dapat dijelaskan berdasarkan hipotesis penurunan sekresi air mata akibat rendahnya estrogen pada wanita menopause, meskipun pada beberapa studi menyatakan bahwa wanita yang menjalani terapi pengganti hormone memiliki faktor risiko lebih tinggi untuk terkena dry eye(Moss, Klein dan Klein, 2008).

Pada penelitian ini didapatkan jumlah responden yang bukan pasien dry eye syndrome sebanyak 11 orang $(36,7 \%)$, dan pasien penderita dry eye syndrome sebanyak 19 orang $(63,3 \%)$. Pengambilan sampel ini bertujuan untuk melihat produksi air mata pada masingmasing kelompok dan membandingkannya, sehingga dapat ditentukan korelasi antara variabel produksi air mata dengan dry eye syndrome pada pasien di poliklinik mata Rumah Sakit Pertamina Bintang Amin Bandar Lampung.

Dari hasil penelitian, didapatkan produksi air mata normal pada responden sebanyak 20 orang $(66,7 \%)$, dan produksi air mata terganggu sebanyak 10 orang $(33,7 \%)$. Penurunan produksi air mata adalah salah satu penyebab dari dry eye syndrome, di samping peningkatan evaporasi. Penurunan produksi cairan aqueus dapat disebabkan oleh Sindroma Sjogren dan bukan Sindroma Sjogren. Pada penyebab bukan Sindroma Sjogren, terjadinya penurunan cairan akuos disebabkan oleh karena gangguan produksi lakrimalis, obstruksi saluran lakrimalis, hambatan reflek kelenjar, dan penggunaan obat-obatan sistemik(Tear Film and Ocular Surface Society, 2007).

Hasil analisis hubungan antara produksi air mata dengan dry eye syndrome diperoleh bahwa di antara 11 responden yang mengalami produksi air mata normal, ada sebanyak 10 orang $(90,9 \%)$ yang bukan pasien dry eye syndrome dan 1 orang $(9,1 \%)$ yang menderita dry eye syndrome. Sementara di antara 19 responden yang mengalami penurunan produksi air mata, ada sebanyak 10 orang $(52,6 \%)$ yang bukan pasien dry eye syndrome dan 9 orang $(47,6 \%)$ yang menderita dry eye syndrome. Hasil uji statistik chi-square diperoleh nilai $p=0,032(<0,05)$, maka Ho ditolak dan dapat disimpulkan bahwa terdapat hubungan antara produksi air matadengan dry eye syndrome. Dari hasil analisis diperoleh pula nilai $\mathrm{OR}=9,00$ artinya responden yang mengalami penurunan produksi air mata mempunyai resiko 9,00 kali lebih besar untuk terkena dry eye syndrome dibandingkan dengan responden yang tidak mengalami penurunan produksi air mata. Nilai confidence interval yang didapat adalah 0,95-84,89. Hal tersebut karena banyak faktor-faktor dari variabel yang tidak diteliti seperti jumlah sampel yang kurang. Sampel yang diteliti kabanyakan pada umur 26 35 tahun, sebaiknya sampel yang usia menopause (46-65 tahun) juga ikut diuji dan juga uji yang dilakukan hanya uji 
schirmer yaitu uji produksi air mata saja.

Hasil ini sesuai dengan teori yang menyebutkan bahwa pada dry eye syndrome, salah satu penyebab utamanya adalah produksi air mata. Penurunan produksi air mata ini dapat disebabkan oleh Sindroma Sjogren dan bukan Sindroma Sjogren. Pada penyebab bukan Sindroma Sjogren, terjadinya penurunan cairan akuos disebabkan oleh karena gangguan produksi lakrimalis, obstruksi saluran lakrimalis, hambatan reflek kelenjar, dan penggunaan obat-obatan sistemik(Tear Film and Ocular Surface Society, 2007).

Hasil penelitian ini sejalan dengan penelitian yang dilakukan oleh Han et al. (2011) yang menunjukkan bahwa penurunan produksi air mata yang dinilai dengan menggunakan uji Schirmer berhubungan dengan kejadian dry eye syndrome $(p=0,04)$. Namun demikian, hasil penelitian ini tidak sesuai dengan penelitian yang dilakukan oleh Sullivan et al. (2014) yang menunjukkan bahwa penilaian produksi air mata dengan menggunakan uji Schirmer tidak berhubungan dengan dry eye syndrome $(p=0,09)$. Dalam kesimpulannya ia menyebutkan bahwa penegakan diagnosa dry eye dengan hanya menggunakan gejala klinis tidaklah tepat, karena membutuhkan evaluasi lebih lanjut melalui pemeriksaan lebih lanjut.

Dalam penelitian ini didapatkan responden yang terdiagnosa dry eye syndrome tetapi memiliki produksi air mata yang normal (1 orang, 9,1\%). Hal ini dapat disebabkan karena dry eye syndrome yang diderita oleh pasien disebabkan oleh faktor lain, yaitu peningkatan evaporasi air mata. Pada penelitian ini juga didapatkan responden yang tidak terdiagnosa dry eye syndrome tetapi mengalami penurunan produksi air mata sebanyak 10 orang $(52,6 \%)$. Hal ini dapat disebabkan karena penurunan produksi air mata yang dialami oleh responden belum sampai ke tahap yang akan menimbulkan gejala, atau dapat disebabkan produksi air mata yang memang secara fisiologis lebih sedikit pada beberapa orang.

\section{Kesimpulan}

1. Distribusi frekuensi produksi air mata pada pasien di Poliklinik Mata Rumah Sakit Pertamina Bintang Amin Bandar Lampung paling banyak pada kategori normal (20 orang, 66,7\%).

2. Distribusi frekuensi penderita dry eye syndrome pada pasien di Poliklinik Mata Rumah Sakit Pertamina Bintang Amin Bandar Lampung paling banyak pada kategori dry eye syndrome (10 orang, 52,6\%).

3. Ada pengaruh yang bermakna antara produksi air mata dengan kejadian dry eye syndrome $(p=0,032)$.

\section{DAFTAR PUSTAKA}

American Academy of Ophtalmology (2014) 'Orbit, Eyelids, and Lacrimal System', Basic and Clinical Science Course.

American Academy of Ophtalmology (2018) What Is Dry Eye? Available at: https://www.aao.org/eyehealth/diseases/what-is-dry-eye (Accessed: 31 July 2018).

Basak, S. K. et al. (2012) 'Prevalence of Dry Eye Diseases in Hospital-based Population in West Bengal Eastern India', $J$ Indian Med Association, 110(11).

Chaironika, N. (2011) Insidensi dan Derajat Dry Eye Pada Menopause di RSU. H. Adam Malik Medan. Skripsi. Tidak Diterbitkan. Fakultas Kedokteran. Universitas Sumatera Utara: Medan.

Craig, J. P. et al. (2017) 'TFOS DEWS II Definition and Classification Report', The Ocular Surface, 15(3), pp. 276-283. doi: 10.1016/j.jtos.2017.05.008.

Dahlan, M. S. (2016) Statistik Untuk Kedokteran dan Kesehatan. 6th edn. Jakarta: Salemba Empat.

Elvira, V. N. W. (2018) 'Penyakit Mata Kering', Continuing Medical Education, Suplemen, pp. 192- 
196.

Firestein, G. S. (2013) Kelley's Textbook of Rheumatology. 9th edn. Philadelphia: Elsevier.

Galor, A. et al. (2014) 'Environmental Factors Affect the Risk of Dry Eye Syndrome in a United States Veteran Population', Ophthalmology, 121(4), pp. 972974. doi: 10.1016/j.ophtha.2013.11.036.

Han, S. B. et al. (2011) 'Prevalence of Dry Eye Disease in an Elderly Korean Population.', Archives of ophthalmology (Chicago, IIl.: 1960), 129(5), pp. 633-8. doi: 10.1001/archophthalmol.2011.78.

Ilyas, S. dan Yulianti, S. R. (2014) I/mu Penyakit Mata. 5th edn. Jakarta: Badan Penerbit Fakultas Kedokteran Universitas Indonesia.

Kanski, J. J. (2011) Clinical Ophtalmology: A Systematic Approach. 7th edn. Edinburgh: Elsevier Butterworth-Heinemann.

Kasetsuwan, N. et al. (2012) 'Prevalence of Dry Eyes in Elderly Thai Population (The Romklao Eye Etudy)', Asian Biomedicine, 6(6), pp. 875-882. doi: 10.5372/19057415.0606 .134$.

Kasetsuwan, N. et al. (2013) 'Incidence and Pattern of Dry Eye after Cataract Surgery', PLOS ONE. Edited by $A$. Wedrich, 8(11), p. e78657. doi: 10.1371/journal.pone.0078657.

Moss, S. E., Klein, R. dan Klein, B. E. K. (2008) 'Long-term Incidence of Dry Eye in an Older Population', Optometry and Vision Science,
85(8), pp. 668-674. doi: 10.1097/OPX.0b013e318181a947.

Notoatmodjo, S. (2012) Metodologi Penelitian Kesehatan. Jakarta: Rineka Cipta.

Riordan-Eva, P. dan Augsburger, J. J. (2017) Vaughan \& Asbury's General Ophtalmology. 19th edn. New York: Mc Graw-Hill Education. doi:

10.1017/CBO9781107415324.004.

Sahai, A. dan Malik, P. (2005) 'Dry Eye: Prevalence and Attributable Risk Factors in a Hospital-Based Population', Indian journal of ophthalmology, 53(2), pp. 87-91. Available at: http://www.ncbi.nlm.nih.gov/pubm ed/15976462 (Accessed: 11 August 2018).

Sullivan, B. D. et al. (2014) 'Correlations Between Commonly Used Objective Signs and Symptoms for The Diagnosis of Dry Eye Disease: Clinical Implications', Acta Ophthalmologica. Wiley/Blackwell (10.1111), 92(2), pp. 161-166. doi: $10.1111 /$ aos.12012.

Tear Film and Ocular Surface Society (2007) '2007 Report of The International Dry Eye Workshop (DEWS)', The Ocular Surface, 5(2), pp. 377-381. doi: 10.1590/S000427492011000500016.

Vision Optique (2015) Layers of The Tear Film. Available at: https://www.visionoptique.com/dry -eye/layers-of-the-tear-film/.

Wagner, P. dan Lang, G. K. (2007) Ophtalmology: A Pocket Textbook Atlas. 2nd edn. New York: Thieme. 